Ethiopian Journal of Environmental Studies \& Management 7(3): 289 - 297, 2014.

ISSN:1998-0507

doi: http://dx.doi.org/10.4314/ejesm.v7i3.8

Submitted: January 18, 2014

Accepted: April 23, 2014

\title{
LEVELS OF ESSENTIAL AND TOXIC METALS IN ETHIOPIAN KHAT, (Catha edulis FORSK.)
}

*AYENEW ASHENEF, 1 GEBREMARIAM BIRHANU, ${ }^{1}$ EPHREM ENGIDAWORK ${ }^{2}$

${ }^{1}$ Department of Pharmaceutical Chemistry and Pharmacognosy, School of Pharmacy, College of Health Sciences, Addis Ababa University, P.o.Box. 1176, Addis Ababa, Ethiopia.

${ }^{2}$ Department of Pharmacology and Clinical pharmacy, School of Pharmacy, College of Health Sciences, Addis Ababa University, P.o.Box. 1176, Addis Ababa, Ethiopia.

\begin{abstract}
Khat chewing is a common habit in East Africa and Arabian Peninsula. However, detail of in-organic elemental content of this plant is scarcely known. Samples of khat (Catha edulis) were collected from different parts of Ethiopia. The leaf parts, which are chewed, were separated and air dried at room temperature. The dried samples were grounded to a fine size by the use of stainless steel mills. One gram was mineralized for metal analysis via digestion in aqua regia under reflux. Spiking was performed to check the accuracy of the digestion procedure. Recoveries varied from $84.5 \%$ to $109.6 \%$. Thirteen metal concentrations were measured by Flame Atomic Absorption/Emission Spectrometer and Graphite Furnace Atomic Absorption Spectrometer employing an external calibration curve. Levels of metals $(\mathrm{mg} / \mathrm{kg})$ on Dried Weight Basis were recorded as follows; Cu: 5.11-9.55 Cd: 0.03-6.54 Pb: non detectable to 1.57 Zn: 4.15-89.3 Mn:6.45-20 K: 5929.65-10948 Na: 218.2842.25 Li: 0.1-0.85 Al: 2448.15-8556.45 Ba: 12.13-1479 Mg: 1798.5.5-3098.75 Fe: 260.95-1551.8 Ca: 2190.910985.8. The possible consumption for the measured elements by chewing khat on regular basis lies within the recommended daily allowance (RDA) except for $\mathrm{Al}$, Fe and Ba. Detection of toxic elements like $\mathrm{Cd}$ and $\mathrm{Pb}$ in khat plant samples investigated might be related to possible introduction of artificial contaminants to the ecosystem of Ethiopia. But the quantities found are in very small amounts thus there should not be an alarm although usual precautions of keeping the environment safe from artificial hazards is necessary. The levels of the analyzed elements in khat that surpassed the RDA i.e. Barium may expose the khat users to damages to heart, blood vessels and nervous system, Iron may facilitate growth of certain pathogenic microorganisms and Aluminium also had unconfirmed correlations under study with neuro-disorders.
\end{abstract}

Key Words: Khat, Catha edulis, Metals, Flame Atomic Absorption/Emission Spectrometer (FAAS), Graphite Furnace Atomic Absorption Spectrometer (GFAAS), Ethiopia.

\section{Introduction}

Khat is the common name for Catha edulis, a dicotyledonous evergreen shrub of the family Celastracea (Al-hebishi and Skaug, 2005). It is also known as Catha, Qaat, Qat, Kat, Chat, Quat, Tschat, Kuses-Salahin, Jaad, Kaad, Gat, Jimaa, Herari, Mirra, Tohai, African Tea, Abyssinian tea, Flower of paradise, Bushman's tea and African salad (Dhaifalah and Santay 2004; Abdusalam et al., 2004).

It is estimated that several million people are habitual khat users, living in geographical areas close to where khat is growing, particularly Yemen, Somalia, Ethiopia, Djibouti and Kenya (Kalix and Braenden, 1985). The overall prevalence of khat chewing in various regions of Ethiopia is well-documented; among upper secondary school students $64.9 \%$ (Adugna et al., 1994), in a rural community in southern Ethiopia $50 \%$ (Alem et al., 1999), at a university located northern Ethiopia, Axum $28.7 \%$ (Gebreslassie, Feleke and Melese 2013), and in the Eastern Ethiopia $24.2 \%$ (Reda et al., 2012). It was reported in a Somalia-based study that approximately $36.4 \%$ of respondents had chewed Khat (Odenwald et al., 2007). Khat use is also widespread in some parts of Yemen, even among children. The prevalence has been estimated at $80 \%$ for males and $50 \%$ for females in the capital Sana'a at age fifteen and above (Basunaid et al., 2008 ) and between 15-20\% of children under the age of 12 (World Bank 2007). Although the government of the Kingdom of Saudi Arabia banned Khat chewing, it remains prevalent in the

*Corresponding Author: Ayenew Ashenef

Email: ayenew.ashenef@ aau.edu.et 
Jazan region. A survey conducted in the region in 2006 revealed that the overall prevalence of chewing Khat was $21.5 \%$ among upper intermediate and high school students compared with $15.2 \%$ of college students (Milaat et al. 2006 and Ageely, 2009). A recent study indicated that the rate of use is at $20.5 \%$ (Alsanosy et al., 2013). Moreover, due to the easiness of human mobility (road networks, air transport and immigration) the habit has spread recently to western countries as far north as Finland (Nencini et al., 1989; Browne, 1991; Tacke et al., 1992).

Depending on the type of khat and the nature of the user, up to $500 \mathrm{gm}$ of fresh edible portion of the leaf might be chewed per day per individual. This amount may be increased in some occasions of celebratory nature (Atlabachew et al., 2010). Thus assessment of its nutrient composition is needed. In particular, the essential, non-essential and toxic metals in khat plants grown in Ethiopia need to be assessed. The metal contents of khat plants grown in Ethiopia have not been studied in depth and there are few reports within this area (Atlabachew et al., 2010, 2011). However, these studies have identified fewer varieties of metallic elements than our study. In addition, the sensitivity of the used analytical instrumentation was inferior of to the graphite furnace atomic absorption spectrometer utilized for this investigation. The latter analytical tool is very sensitive enabling detection of some toxic elements which were not identified in previous evaluations.

This study is therefore intended to assess levels of essential, non-essential and toxic metals in khat leaves that are grown in different localities of Ethiopia using atomic absorption flame emission spectrophotometer and graphite furnace atomic absorption spectrometry. The study is expected to deliver preliminary data on the levels of metals in khat plants grown in Ethiopia and provide useful information for future studies which will be conducted on the medical and toxicological effects in relation to the khat plant varieties grown in Ethiopia.

\section{Materials and Methods}

\section{Calibration Curves}

The calibration curves used for metal analysis showed a very good correlation coefficient (R) which is in between $0.995-1$ in all the experimental analysis cases. A minimum of five concentration points were also considered for constructing the calibration curve.

\section{Method Validation}

Spiking was performed to validate the accuracy of the digestion procedure and percent recovery is a good indicator of it. It was found to be in the range $90-110 \%$ except for lithium in one Khat sample. This is in agreement with most analytical recommendations for metal measurement. The lower percent recovery for lithium may be attributed to its very low concentration in which other sensitive analytical methods may be needed, such as inductively coupled plasma mass spectrometry, ion chromatography with sensitive detection. The limit of detection (LOD) and the limit of quantification (LOQ) are calculated based on the following formulas. $\mathrm{LOD}=3 \sigma / \mathrm{b}$ while $\mathrm{LOQ}=10$ $\sigma / \mathrm{b}$, the symbols denotation are: $\sigma=$ standard deviation of the blank analyses and $b=$ slope of the calibration curve. The repeated number of measurements made (n) for were 12. Moreover by analyzing the samples in triplicates the relative standard deviation was calculated as a measure of precision. The LOD and LOQ values for $\mathrm{pb}, \mathrm{Cu}$, $\mathrm{Cd}, \mathrm{Ba}, \mathrm{Al}, \mathrm{Li}, \mathrm{Na}, \mathrm{Ca}, \mathrm{Mg}, \mathrm{K}, \mathrm{Zn}, \mathrm{Mn}$ and $\mathrm{Fe}$ were found as $0.0022,0.003,0.0019$. 0.003, $0.003,0.0019,0.070,0.005,0.080 .0 .002, .0 .003$, $.0 .003, .0 .07$ and $0.0072,0.0099,0.0062,0.0099$, $0.0099, .0 .0062,0.231, .0 .016, .0 .264,0.0066$, . $0.0099,0.0099,0.231 \mathrm{mg} / \mathrm{kg}$ respectively.

\section{Sample Collection}

Khat plant materials were collected from different locations of Ethiopia and brought to the laboratory wrapped in polyethylene bags. The places were Bahir Dar South, from the southern part of Bahir Dar town near the airport, Amhara region; Bahir Dar North, from the northern part of the town; Hirina from Hirina town, West Harerghe, Oromia region; Beleche from Beleche locality, Sidama zone, Southern Peoples Nations and Nationalities(SPNNs) region; Gelemso from Gelemso town, West Harerghe zone, Oromia region; Wendo from wendo town, Sidama zone, SPNNs region; Indibir type from Indibir town, Guraghe zone, SPNNs region; Addis Ababa from Addis Ababa city, grown in a home garden around Asko locality, Addis Ababa; Alemaya from Alemaya town, west Harerghe, Oromia region; Beleche type, Purchased from Addis Ababa city in a shop located at Arada sub city. 
The samples were purchased from the local shops (Kiosks) in which are locally called "Khat Suq" meaning "Khat shop" but for Bahir Dar and Addis home garden khats, the samples were collected from their growing places.

Respective herbarium specimens were deposited under "Ayenew Ashenef" with identification numbers AA01-AA10 in the National Herbarium in the order mentioned above, Department of Biology, Addis Ababa University, Ethiopia. Verification was done by Mr. Melaku Wondafrash. In the laboratory, the khat leaves were washed with deionised water. The leaves were dried at room temperature. The dried samples were then grinded to fine size using two sequential millers; Mill one (2.00 mm mesh size) and Mill two (1.00 $\mathrm{mm}$ mesh size). The powders were subsequently stored in clean polyethylene bags until digestion. To avoid cross contamination, the stainless steel grinding system of the millers were washed with acetone after or before each grinding cycle.

\section{Sample Digestion}

All the glassware, polyethylene bottles and other apparatuses used were carefully cleaned and then rinsed in aqua regia overnight and washed with deionized water prior to use.

Sample solutions were made for metal analysis following the standard procedure recommended by the Royal Committee of experts for the digestion of plant materials (Standing Committee for Analysis 1987). Briefly, $1 \mathrm{~g}$ of powdered sample, $10 \mathrm{~mL}$ of freshly prepared aqua regia was added. The solution was refluxed for $30 \mathrm{~min}$ on a heating mantle using round bottom flask (Buchi, $100 \mathrm{ml}$ ) fitted with a condenser with cool water circulating in it. The temperature varies from $105-110{ }^{\circ} \mathrm{C}$ throughout the heating process. After $30 \mathrm{~min}$, the sample in the flask was removed and cooled down to room temperature. $20 \mathrm{~mL}$ of deionized water was added and the solution was filtered using filter paper and then diluted up to $50 \mathrm{~mL}$ with deionized water. Sample solutions were then stored in clean polyethylene bottles for metal analysis and stored in a refrigerator until analysis.

\section{Metal Analysis}

The samples were analyzed after digestion for their metal contents of $\mathrm{Cu}, \mathrm{Cd}$ and $\mathrm{Pb}$ by the use of Graphite furnace atomic absorption spectrometer using aqueous external calibration standards. The standards were prepared by systematically diluting $1000 \mathrm{ppm}$ stock solutions of the respective elements. Similarly for other elements, $\mathrm{Na}, \mathrm{Li}, \mathrm{K}, \mathrm{Ca}, \mathrm{Mg}, \mathrm{Ba}, \mathrm{Zn}, \mathrm{Mn}, \mathrm{Al}$, and $\mathrm{Fe}$ were determined in the samples by Flame Atomic Absorption/Emission Spectrometer after an external calibration using aqueous calibration standards prepared from stock standard solutions of the respective elements either in emission mode for the first three or in absorbance mode for the last seven elements. Systematic dilutions were performed using deionized water. Reagent blanks were prepared in the same manner by refluxing and used as blank measurements. Spiking was performed for each element in two khat samples as a method validation tool of the metal analysis procedure. The instrumental parameters were set as per the manufacturer's recommendations.

\section{Data Analysis}

One way ANOVA coupled with Post hoc Student-Newman-keul's test was performed in order to compare the mean values of each element in khat sources. Microsoft Excel (Microsoft Corp., Redmond Campus, WA 980526399, Washington, USA) was used to calculate the descriptive statistics (like mean, standard deviation), Origin 7 (Origin Lab corporation, One round house plaza, Northampton, MA 01060, USA) to draw the graph and Instat (GraphPad Software, Inc. 7825 Fay Avenue, Suite $230 \mathrm{La}$ Jolla, CA 92037 USA) to perform the ANOVA analysis as well as the Post hoc Newman-Keuls pair wise comparison test. $\mathrm{P}<0.05$ was used as a cutoff point to show significance difference.

\section{Results and Discussion Metal Levels}

The level of $\mathrm{Cu}$ in Khat samples varies from $5.44 \mathrm{mg} / \mathrm{Kg}$ to $9.05 \mathrm{mg} / \mathrm{Kg}$. The smallest and biggest amounts were found in samples obtained from Addis Ababa and Bahir Dar near the airport respectively as shown in table 1 . The order of abundance for Copper in the samples were Addis Ababa, Indibir, Gelemso, Beleche Addis, Alemaya, Wondo, Hirina, Bahir Dar north, Beleche origin, Bahir Dar airport from lowest to the highest quantity.

Cadmium is a toxic element and its presence was detected and quantified in all Khat samples. The concentrations detected were not of a concern although relatively high levels were 
detected for Khat samples collected in Bahir Dar near the airport. Airport and military activities might be responsible for such higher value. Emission of cadmium into the environment can result from incineration of metal scrap, use of phosphate fertilizers, metal plating activities and abrasion from automobile tyres (Ndiokwere, 1984). As seen in table 1, the overall range in both Khat samples for cadmium is 0.02-4.55 $\mathrm{mg} / \mathrm{kg}$. In other vegetable samples (Cabbage, Silver beet, Lettuce, Carrots, and Kale) in Ethiopia, Gondar and Addis Ababa, Cd level ranges from 0.009 to $12.70 \mathrm{mg} \mathrm{kg}^{-1}$ (Rahlenbeck et al., 1999). Other study reported Cd levels to be $0.02-0.13 \mathrm{mg} \mathrm{kg}^{-1}$ from leafy vegetables in Addis Ababa (Itanna, 2002). One way ANOVA test indicates the variations in the cadmium content among the Khat samples was significant. The Student-Newman Keul's test for pair-wise comparison demonstrates that only $\mathrm{Cd}$ levels in Khat sample obtained from Bahir Dar near the airport versus the other samples is extremely significant $(\mathrm{P}<0.001)$. The remaining pairs were non-significant $(\mathrm{P}>0.05)$.

Lead was not detectable in more than half of the analyzed samples despite the use of the more sensitive analytical technique GFAAS. Lead is a toxic metal and its absence could be considered an advantage. However, below detection limit does not imply lead is completely absent. In addition, the level of lead in Khat samples range from $0.414-2.18 \mathrm{mg} / \mathrm{kg}$; only three samples out of ten (Khat Addis Ababa, Khat Bahir Dar north near Blue Nile bridge and Khat Gelemso) lead was quantified. The relative industrialization in Addis Ababa and Bahir Dar may be one possible reason for such results while no reasonable explanation could be rationalized Gelemso's case. The lead content of Ethiopian vegetables was reported to vary from $0.02-27.52 \mathrm{mg} \mathrm{kg}^{-1}$ (Rahlenbeck et al., 1999) and 0.21-1.79 mg kg-1 (Itanna, 2002). Our result is in agreement with the latter study. The transfer rate of lead from soil to plants is lesser than cadmium despite exposure (Zuera et al., 1987; Jackson and Alloway, 1991). This may explain why there are similar lead values in the two studies but higher cadmium value in the current study although anthropogenic sources of contamination increase from time to time. In fact environmental lead pollution occurs primarily through traffic emissions. Lead contents in gasoline sold in African countries remained high (Nriagu, 1992). Each sample complies with the theoretical daily allowance level for the possible average daily chewing of Khat for those habitual users. In those samples where lead is detected the ranking was as follows; Addis > Gelemso $>$ Bahir Dar north.

The amount of zinc in Khat samples varies from $9.5 \mathrm{mg} / \mathrm{kg}-197.5 \mathrm{mg} / \mathrm{kg}$. Some khat samples contain apparently uniform zinc levels. Some plants have constant reuptake of certain elements in spite of exposure (Chambers and Sidle, 1991). Catha edulis may have similar accumulative nature to Zinc as the geographical variation does not bring significant change in its content of Zinc.

Highest level of zinc is shown among the samples in the study for Indibir khat while the Beleche type purchased in Addis exhibited the lowest value. Although the two are the same type due to any variations in soil and water content of zinc, human impact and other factors in the above locality, the level of zinc in Beleche type of Khat is highly different in the two samples analyzed (the one purchased in Addis and the one bought from the nearby site). This was further confirmed in the two Khat samples brought from Bahir Dar.

Manganese was quantified in a uniform level in Khat samples (6.15 mg/kg-19 mg/kg. Manganese exposure can play an important role in causing parkinsonian disturbances, possibly enhancing physiological aging of the brain in conjunction with genetic predisposition. An increased environmental burden of manganese may have deleterious effects on more sensitive subgroups of the population, with sub-threshold neuro-degeneration in the basal ganglia, generating a pre-parkinsonian condition (Zatta et al., 2003). But manganese (Mn) is an essential mineral.

Barium is a dense alkaline earth metal that exists in nature as a divalent cation in combination with other elements. The level of Barium in the samples analyzed varies from $12.8 \mathrm{mg} / \mathrm{kg}$ to $1398.5 \mathrm{mg} / \mathrm{kg}$ as shown in the table 1. The minimum is from Gelemso sample while the maximum was recorded in Beleche Khat sample purchased in Addis Ababa. Although unacceptable levels of Barium are found in both Khat samples, its bioavailability should be assessed as individuals may be exposed to higher amount of barium sulfate as a contrasting media 
and still tolerate it due to its poor absorption in humans. Although no in vivo data are available, in vitro data indicate that barium compounds have no mutagenic potential (Choudhury and Cary, 2001 ).

Lithium is used in the prophylaxis of manicdepressive (bipolar) and recurrent unipolar depressive disorders (BNF, 1999). In this study, very low levels of lithium were found in all khat samples analyzed (Table 2).

Although very little is known about its biological effects in the human body, there have been suggestions of a link between $\mathrm{Al}$ and Alzheimer's disease (Candy et al., 1986). Aluminum has long been known as a neurotoxin agent. It is an etiopathogenic factor in diseases related to long-term dialysis treatment, and it has been controversially invoked as an aggravating factor or cofactor in Alzheimer's disease as well as in other neurodegenerative diseases (Zatta et al.2003).It is found in khat samples investigated from $2579 \mathrm{mg} / \mathrm{kg}$ up to $8250 \mathrm{mg} / \mathrm{kg}$ as shown in table 2 .

Iron is an essential element. As shown in table 4, it was found in the level of 273.05 $\mathrm{mg} / \mathrm{kg}-1497.5 \mathrm{mg} / \mathrm{kg}$ in Khat. But Iron toxicity, caused by over absorption and accumulation of iron, can result in severe liver and heart damage (Ensminger et al., 1995; Wardlaw and Insel 1996; Fifield and Haines, 1997).The variations among Khat samples is significant $(\mathrm{P}<0.0001$, one way ANOVA).

Potassium was also found in khat samples at a level of $5,955 \mathrm{mg} / \mathrm{kg}-10,880 \mathrm{mg} / \mathrm{kg}$. However, being an essential element, the nutritive importance should be emphasized. Minimum and maximum values were both from Khat samples of Addis Ababa and Bahir Dar origin. The values are also similar to each other which are further confirmed by the pairwise comparison in which only some samples differ in four pairs.

The level of sodium in Khat samples ranges from 225.7 to $836.5 \mathrm{mg} / \mathrm{kg}$. In the investigated samples, the minimum was found in Beleche purchased from Addis and the maximum in khat of Addis Ababa origin. Calcium is an abundant element found in good quantities in both Khat samples. The value of calcium in Khat ranges from 2212 to $10860 \mathrm{mg} / \mathrm{kg}$. Ca levels among khat samples varied considerably. The level of
Magnesium in Khat ranges from 1810.5 to 3057.5 $\mathrm{mg} / \mathrm{kg}$. The values are shown in Table 3 .

Averages were computed for the whole Khat samples as shown in Figure 1. One way ANOVA statistical comparison was then performed. The differences in the means of the levels of metals in Khat samples were insignificant for $\mathrm{Li}, \mathrm{Al}, \mathrm{Fe}, \mathrm{K}$, $\mathrm{Ba}, \mathrm{Cd}, \mathrm{Cu}$ and $\mathrm{Ba}$ while extreme significant variation observed in $\mathrm{Pb} \quad(\mathrm{P}<0.001), \quad \mathrm{Mn}$ $(\mathrm{P}<0.001), \quad \mathrm{Na} \quad(\mathrm{P}<0.001), \quad \mathrm{Ca} \quad(\mathrm{P}<0.001), \quad \mathrm{Mg}$ $(\mathrm{P}<0.001)$. Post hoc test with Student-Newman Keul's further describe the significance for both three groups in case of $\mathrm{Pb}$ while for $\mathrm{Ca}, \mathrm{Mg}, \mathrm{F}$, $\mathrm{Mn}$ and $\mathrm{Zn}$ the significant difference is with respect to Khat Samples.

\section{Possible Intake}

Calculations were performed based on the fact that an average chewer chews 100-200 gm Khat leaves per day on wet weight basis (Kalix, 1996) and the moisture content is $85 \%$ hence 15 $30 \mathrm{gm}$ on dried weight basis. As shown in table 4, the values for most metals are within the acceptable range. However, this was not the case for Iron, Aluminium and Barium where the exposure level bypasses the acceptable limit. Therefore, khat chewers are at risk of the health hazards related to these metals. Moreover the RDA for metals is a whole some picture of any source (food, water etc) where each daily intake contributes. Hence, although independently the values for other elements did not surpass the limits by Khat, It does not warrant their contribution to cumulative metal exposure with the other sources is negligible. Detection of the very toxic metal, cadmium, in all the samples of Khat is of a great concern.

Moreover, as people may have some health problems which may restrict the consumption of electrolytes, knowing the level of these elements in samples consumed is critical. The toxic metals should be thoroughly surveyed in order to take any remedial actions. Control authorities in the national government positions and international bodies should be aware of such issues and take appropriate measures.

\section{Conclusion}

In this study the elemental composition of many elements in khat were successfully quantified. Unlike many reports in Ethiopian fauna, by the use of the more sensitive graphite furnace absorption spectrometer, it was possible 
to detect some toxic elements like lead and cadmium. Among the studied elements, the order of abundance was found to be as follows $\mathrm{K}>\mathrm{Ca}>\mathrm{Al}>\mathrm{Mg}>\mathrm{Na}>\mathrm{Ba}>\mathrm{Fe}>\mathrm{Zn}>\mathrm{Mn}>\mathrm{Cu}>\mathrm{Pb}>\mathrm{Cd}$ $>\mathrm{Li}$ (figure 1). This is in line with their traceness in nature as well as their toxicity profile.

Although khat consumption is not an encouraged practice, its epidemiology is very high in parts of East Africa and Arabian Peninsula, and thus habitual people are unnecessarily exposing themselves to some elements namely barium, Aluminium and Iron, which are abundant and the average consumer takes them above the recommended daily allowance. Hence chewers may expose themselves to the risks posed by these elements.

\section{Acknowledgements}

The authors are grateful to Addis Ababa University for funding this research. We are thankful to the Department of Earth sciences of Addis Ababa University and EPHARM S.C. for allowing us to use their facilities.

\section{References}

Abdusalam, A., Jian-Kai, Z. and Xue-feng, Y. (2004). Solid phase microextraction for flavor analysis in Harari Khat (Catha edulis) stimulant. Journal of Zheijiang University Science 5(4): 428-431.

Adugna, F., Jira, C. and Molla, T. (1994). Khat chewing among Agaro Secondary School students, Agaro, South Western Ethiopia. Ethiopian Medical Journal 32: 161-166.

Ageely, H.M. (2009). Prevalence of Khat chewing in college and secondary (high) school students of Jazan region, Saudi Arabia. Harm Reduction Journal 6: 11. doi:10.1186/1477-7517-6-11

Alem, A., Kebede, D. and Kullgren, G. (1999). The prevalence and socio-demographic correlates of Khat chewing in Butajira, Ethiopia. Acta Psychiatrica Scandivica (Suppl) 100: 84-91.

Al-hebshi, N and Skaug, N. (2005). Effect of khat-chewing on selected periodontal bacteria in sub- and supragingival plaque of a young male population. Oral Microbiology and Immunology 20:141 146.
Alsanosy, R. M., Mahfouz, M.S. and Gaffar, A.M. (2013), Khat Chewing Habit among School Students of Jazan Region, Saudi Arabia. PLOS ONE 8(6):e65504. doi:10.1371/journal.pone.0065504.

Atlabachew, M., Chandravanshi, B.S. and Redi, M. (2010). Concentration levels of essential and non-essential metals in Ethiopian Khat (Catha edulis Forsk.). Biological Trace Element Research 138:316-325.

Atlabachew, M., Chandravanshi, B.S. and Redi, M. (2011). Profiles of Major, Minor and Toxic metals in soil and Khat (Catha edulis Forsk) cultivars in Ethiopia. Trends in Applied Sciences research. 6(7):640-655.

Basunaid, S., Van Dongen, M. and Cleophas, T.J. (2008). Khat abuse in Yemen: A population-based survey. Clinical Research and Regulatory Affairs. 25:87-92.

BNF (British National Formulary) (1999). British Medical Association Publication group. UK.

Browne, D.L. (1991). Qat use in New York City. NIDA Research Monographs105:464 465.

Candy, J.M., Klinowski, J., Perry, R.H., Perry, E. K., Fairburn, A., Oakley, A.E., Carpenter, T.A., Atack, J.R., Blessed, G. and Edwardson, J.A. (1986). Aluminosilicates and senile plaque formation in Alzheimer's disease. Lancet i, 354-357.

Chambers, J. and Sidle, R. (1991). Fate of heavy metals in an abandoned lead-zinc tailings pond, vegetation. Journal of Environmental Quality 20:745-778.

Choudhury, H. and Cary, R. (2001). Concise International chemical Assessment Document 33 a publication of WHO , UNEP and ILO, Wissenschaftliche Verlagsgesellschaft $\quad \mathrm{GmbH}, \quad$ D-70009 Stuttgart $10 \mathrm{pp}$ 4-6.

Dhaifalah, I. and Santay, J. (2004). Khat Habit and its Health Effect. A natural amphetamine. Biomedical Papers 148(1): 11-15.

Ensminger, M.E., Ensminger, A.H., Konlnde, J.E. and Robson, J.K.. (1995). The Concise Encyclopedia of Food and Nutrition; CRC Press: Boca Roton: pp 712-722.

Fifield, F.W, Haines, P.J. (Eds.). (1997). Environmental Analytical Chemistry, 
Blackie Academic and Professional: London: PP 323 -349.

Gebreselassie, M., Feleke, A. and Melese, T. (2013). Psychoactive substances use and associated factors among Axum university students, Axum Town, North Ethiopia BMC Public Health, 13:693.doi:10.1186/1471-2458-13-693.

Itanna, F. (2002). Metals in leafy vegetables grown in Addis Ababa and toxicological implications Ethiopian Journal of Health Development 16(3):295-302.

Jackson, A.P. and Alloway, B.J. (1991). The bioavailability of Cadmium to lettuce and Cabbage in soils previously treated with sewage sludges. Plant soil132:179-186.

Joint FAO/WHO Expert Committee on Food Additives (1999). Summary and conclusions, in: $53^{\text {rd }}$ meeting, Rome, June 1-10, 1999.

Kalix, P. (1996) Catha edulis, a plant that has amphetamine effects. Pharmacy World Science 18:69-73.

Milaat, A.A., Bani, I.A., Ageely, H.M. and ElNaggar, M.M. (2006). Assessment of Health risk factors and social problems associated with Khat use in Jazan region, research report, King Abdulaziz University, KSA.

Ndiokwere, C.L. (1984). A study of heavy metal pollution from motor vehicle emissions and its effect on road side soil, vegetation and crops in Nigeria. Environ Poll.(Ser.B) 7:3542.

Nencini, P., Grassi, M.C., Botan, A.A., Asseyr. A.F and Paroli, E. (1989). Khat chewing spread to the Somali community in Rome. Drug and Alcohol Dependence 23:255 258.

Nriagu, J.O. (1992). Toxic metal pollution in Africa. Science of Total Environment 121:1-37.

Odenwald, M., Hinkel, H., Schauer, E., Neuner, F., Schauer, M., Elbert, T.R. and
Rockstroh, B. (2007). The Consumption of Khat and Other Drugs in Somali Combatants: A Cross-Sectional Study. PLoS Med 4(12)ne341. doi:10.1371/journal.pmed.0040341.

Rahlenbeck, S.I., Burberg, A. and Zimmerman, D. (1999). Lead and Cadmium in Ethiopian Vegetables Buletin of Environmental Contamination and Toxicology 62:30-33.

Reda, A.A., Moges, A., Biadgilign, S. and Wondmagegn, B.Y. (2012). Prevalence and Determinants of Khat (Catha edulis) Chewing among High School Students in Eastern Ethiopia: A Cross-Sectional Study. PLoS ONE 7(3): e33946. doi:10.1371/journal.pone.0033946.

Standing Committee of Analysis. (1987). Method for the determination of metals in soils, sediments and sewedge sludge and plants by hydrochloric-nitric acid digestion, with a note on the determination of the insoluble metal contents. Method for the examination of waters and other materials. Her Majesty's Office, London.

Tacke, U., Malinen, H. and Pitkanen, H. (1992). [Khat-a new drug in Finland]. Duodecim 108:1390 - 1394.

Wardlaw, G.M. and Insel, P.M. (1996). Perspective in Nutrition, 3rd ed., MosbyYear, Boston. PP 76-85.

World Bank (2007). World Bank Report. Yementowards qat demand reduction. Report No. 39738- Ref Type: Report.

Zatta, P., Lucchini, R., van Rensburg, S.J. and Taylor, A. (2003). The role of metals in neurodegenerative processes: aluminum, manganese, and zinc. Brain Research Bulletin 62: 15-28.

Zurera, G., Estrada, B., Racon, F. and Pozo, F. (1987) Lead and Cadmium contamination levels in edible vegetables. Bulletin of Environmental Contamination and Toxicology 38: 805-812. 


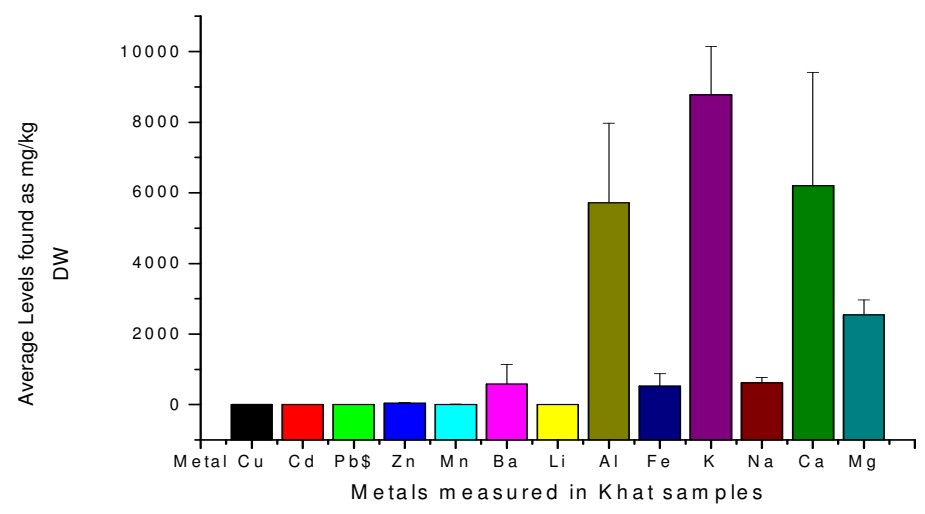

\$: denotes averaging for lead was done only considering those samples where it was detected. DW: dried weight.

Figure 1: Diagrammatical representation of the average levels of metals found in the Khat Samples Investigated.

Table 1: Amount of $\mathrm{Cu}, \mathrm{Pb}, \mathrm{Cd}$ and $\mathrm{Zn}$ in Khat Samples as Mean $\pm \mathrm{SD}$ (\%RSD) of Triplicate Measurements in $\mathrm{mg} / \mathrm{kg}$ of Sample on Dried Weight Basis

\begin{tabular}{|c|c|c|c|c|}
\hline Sample & Copper & Lead & Cadmium & Zinc \\
\hline Addis Ababa & $5.44 \pm 0.26(4.71)$ & $1.24 \pm 0.33(26.71)$ & $0.90 \pm 0.52(58.45)$ & $41.35 \pm 0.8(1.9)$ \\
\hline Alemaya & $7.16 \pm 0.05(0.77)$ & NDL & $0.24 \pm 0.14(58.41)$ & $40.8 \pm 0.9(2.18)$ \\
\hline Beleche from & $6.97 \pm 0.06(0.82)$ & NDL & $1.75 \pm 0.37(21.46)$ & $14.45 \pm 1.6(11)$ \\
\hline Addis market & & & & \\
\hline $\begin{array}{l}\text { Bahir Dar Near air } \\
\text { port }\end{array}$ & $9.05 \pm 0.50(5.47)$ & NDL & $4.55 \pm 1.99(43.97)$ & $15.15 \pm 1(6.67)$ \\
\hline $\begin{array}{l}\text { Bahir Dar khat } \\
\text { North }\end{array}$ & $7.87 \pm 0.06(0.77)$ & $0.54 \pm 0.17(31.24)$ & $0.091 \pm 0.02(21.93)$ & $35.55 \pm 1.95(5.46)$ \\
\hline $\begin{array}{l}\text { Beleche Khat from } \\
\text { the origin }\end{array}$ & $8.14 \pm 0.006(0.07)$ & NDL & $0.16 \pm 0.028(17.85)$ & $49.2 \pm 2.3(4.64)$ \\
\hline Gelemso khat & $6.92 \pm 0.29(4.16)$ & $1.12 \pm 0.14(12.75)$ & $0.59 \pm 0.53(89.54)$ & $52.95 \pm 1.7(3.2)$ \\
\hline Hirina Khat & $7.55 \pm 0.22(2.85)$ & NDL & $0.256 \pm 0.06(23.06)$ & $43.45 \pm 2.35(3.39)$ \\
\hline Indibir Khat & $5.46 \pm 0.35(6.31)$ & NDL & $0.11 \pm 0.08(73.61)$ & $87.6 \pm 1.7(3.2)$ \\
\hline Wendo & $7.18 \pm 0.114(1.59)$ & NDL & $0.25 \pm 0.09(35.11)$ & $29.3 \pm 1(3.43)$ \\
\hline
\end{tabular}

NDL: Not Detectable

Table 2: Amount of $\mathrm{Mn}, \mathrm{Ba}, \mathrm{Li}$ and $\mathrm{Al}$ in Khat Samples as Mean $\pm \mathrm{SD}$ (\%RSD) of Triplicate Measurements in $\mathrm{mg} / \mathrm{kg}$ of Sample on Dried Weight Basis

\begin{tabular}{|c|c|c|c|c|}
\hline Sample & Manganese & Barium & Lithium & Aluminium \\
\hline Addis Ababa & $19 \pm 1(5.33)$ & $31.05 \pm 0.7(2.25)$ & $0.85 \pm 0$ & $8012 \pm 86.53(1.08)$ \\
\hline Alemaya & $13.85 \pm 1.15(8.31)$ & $1299 \pm 68.45(5.27)$ & $0.4 \pm 0$ & $4850.5 \pm 458.35(9.45)$ \\
\hline $\begin{array}{l}\text { Beleche from Addis } \\
\text { market }\end{array}$ & $15.75 \pm 0.8(5.12)$ & $1398.5 \pm 80.5(5.76)$ & $0.1 \pm 0$ & $2796 \pm 347.85(12.44)$ \\
\hline Bahir Dar Near air port & $10.4 \pm 0.75(7.18)$ & $256.35 \pm 112(43.68)$ & $0.63 \pm 0.023$ & $3691.5 \pm 95.6(2.59)$ \\
\hline Bahir Dar Khat North & $6.15 \pm 1.3(20.96)$ & $766 \pm 110.15(14.37)$ & $0.55 \pm 0$ & $8250 \pm 306.45(3.72)$ \\
\hline $\begin{array}{l}\text { Beleche Khat from the } \\
\text { origin }\end{array}$ & $7.55 \pm 0.7(9.52)$ & $986 \pm 72.2(7.32)$ & $0.48 \pm 0.023$ & $8205 \pm 150.55(1.83)$ \\
\hline Gelemso Khat & $9.1 \pm 1(10.76)$ & $12.8 \pm 0.67(5.19)$ & $0.28 \pm 0.02$ & $5875 \pm 148.05(2.52)$ \\
\hline Hirina Khat & $16.2 \pm 1.45(9.06)$ & $998.5 \pm 113.05(11.32)$ & $0.77 \pm 0.02$ & $7720 \pm 127.38(1.65)$ \\
\hline Indibir Khat & $7.5 \pm 1.05(13.85)$ & $24.45 \pm 0.95(3.97)$ & $0.53 \pm 0.02$ & $5270 \pm 398.15(7.56)$ \\
\hline Wendo & $10.9 \pm 1.55(13.98)$ & $28.55 \pm 0.75(2.62)$ & $0.23 \pm 0.02$ & $2579 \pm 30.55(1.18)$ \\
\hline
\end{tabular}


Table 3: Level of Fe, K, Na, Ca and Mg in Khat Samples as Mean \pm SD (\%RSD) of Triplicate Measurements in $\mathrm{mg} / \mathrm{kg}$ of Sample on Dried Weight Basis.

\begin{tabular}{llllll}
\hline Sample & Iron & Potassium & Sodium & Calcium & Magnesium \\
\hline $\begin{array}{l}\text { Addis Ababa } \\
\text { Alemaya }\end{array}$ & $667.5 \pm 16.4(2.46)$ & $5955 \pm 25.35(0.43)$ & $836.5 \pm 5.75(0.69)$ & $10860 \pm 66.1(0.61)$ & $2800 \pm 34.1(1.22)$ \\
$\begin{array}{l}\text { Beleche from } \\
\text { Addis market }\end{array}$ & $335 \pm 26.35(7.86)$ & $8320 \pm 49.85(0.6)$ & $225.7 \pm 7.5(3.31)$ & $2212 \pm 21.1(0.95)$ & $2170 \pm 19.35(0.89)$ \\
$\begin{array}{l}\text { Bahir Dar Near } \\
\text { air port }\end{array}$ & $276.3 \pm 9.2(3.33)$ & $9010 \pm 174.75(1.94)$ & $659 \pm 3.9(0.59)$ & $5220 \pm 71.15(1.36)$ & $2731.5 \pm 19.75(0.72)$ \\
Bahir Dar Khat & $407.65 \pm 33.15(8.14)$ & $10880 \pm 68(0.63)$ & $626 \pm 6.85(1.1)$ & $5040 \pm 42.35(0.84)$ & $3055.5 \pm 14.3(0.47)$ \\
$\begin{array}{l}\text { North } \\
\text { Beleche Khat }\end{array}$ & $531.5 \pm 5.75(1.08)$ & $7645 \pm 60.5(0.79)$ & $682 \pm 4.05(0.59)$ & $3242.5 \pm 44.9(1.39)$ & $2464.5 \pm 6.2(0.25)$ \\
from the origin & & & & & \\
$\begin{array}{l}\text { Gelemso Khat } \\
\text { Hirina Khat }\end{array}$ & $351.15 \pm 14.5(4.13)$ & $9690 \pm 164.35(1.7)$ & $634 \pm 1.75(0.28)$ & $7750 \pm 69(0.89)$ & $2907 \pm 11.9(0.41)$ \\
$\begin{array}{l}\text { Indibir Khat } \\
\text { Wendo }\end{array}$ & $432.8 \pm 28.65(6.62)$ & $8305 \pm 93.6(1.13)$ & $512 \pm 3.5(0.68)$ & $3271 \pm 72.75(2.22)$ & $2162.5 \pm 18.2(0.84)$ \\
& $273.05 \pm 12.1(4.43)$ & $8405 \pm 44.55(0.53)$ & $572 \pm 2.2(0.38)$ & $3774 \pm 50.65(1.34)$ & $1810.5 \pm 12(0.66)$ \\
\hline
\end{tabular}

Table 4: Possible intake of the metals studied for an average Khat consumer and its comparison with RDA standards Metal Average amount found Possible intake by RDA/PMDWI Remark

\begin{tabular}{lllll} 
& in Khat & average consumer & & \\
\hline $\mathrm{Cu}$ & $7.17 \pm 1.11$ & $107.55-215.1$ & 3000 & $\mathrm{BL}$ \\
$\mathrm{Cd}$ & $0.87 \pm 1.44$ & $13.05-26.1$ & 60 & $\mathrm{BL}$ \\
$\mathrm{Pb} \$$ & $0.97 \pm 0.37$ & $14.55-29.1$ & 214 & $\mathrm{BL}$ \\
$\mathrm{Zn}$ & $40.98 \pm 20.2$ & $614.7-1229.4$ & 60000 & $\mathrm{BL}$ \\
$\mathrm{Mn}$ & $11.64 \pm 4.28$ & $174.6-349.2$ & 2000 & $\mathrm{BL}$ \\
$\mathrm{Ba}$ & $580.18 \pm 551.31$ & $8702.7-17405.4$ & 1400 & $\mathrm{AL}$ \\
$\mathrm{Li}$ & $0.48 \pm 0.23$ & $7.2-14.4$ & 1000 & $\mathrm{BL}$ \\
$\mathrm{Al}$ & $5724.9 \pm 2244.5$ & $85873.5-171147$ & 5000 & $\mathrm{AL}$ \\
$\mathrm{Fe}$ & $529.13 \pm 350.03$ & $7936.95-15873.9$ & 10000 & $\mathrm{AL}$ \\
$\mathrm{K}$ & $8776 \pm 1372.53$ & $131640-263280$ & $2000000-3100000$ & $\mathrm{BL}$ \\
$\mathrm{Na}$ & $613.96 \pm 157.18$ & $9209.4-18418.8$ & 500000 & $\mathrm{BL}$ \\
$\mathrm{Ca}$ & $6198.4 \pm 3215.82$ & $92976-185952$ & $800000-1300000$ & $\mathrm{BL}$ \\
$\mathrm{Mg}$ & $2542.7 \pm 415.98$ & $38140.5-76281$ & $300000-400000$ & $\mathrm{BL}$ \\
\hline $\mathrm{AL}$ & & & \\
\hline
\end{tabular}

$\mathrm{AL}$; Above limit BL: Below Limit. \$ those samples where $\mathrm{Pb}$ is detected are only averaged; unit of measurement is $\mu \mathrm{g}$, $\mathrm{RDA}=$ recommended daily allowance, $\mathrm{PMDWI}=$ provisional maximum tolerable daily intake for toxic elements i.e. $\mathrm{Cd}$ and $\mathrm{Pb}$ (Joint FAO/WHO, 1999) 